\title{
Continental heat gain in the global climate system
}

\author{
Hugo Beltrami \\ Department of Earth Sciences, St. Francis Xavier University, Antigonish, Nova Scotia, Canada
}

Jason E. Smerdon

Applied Physics Program, University of Michigan, Ann Arbor, MI, USA

\author{
Henry N. Pollack and Shaopeng Huang \\ Department of Geological Sciences, University of Michigan, Ann Arbor, MI, USA
}

Received 1 January 2001; revised 23 January 2002; accepted 2 February 2002; published 17 April 2002.

[1] Recent estimates have shown the heat gained by the ocean, atmosphere, and cryosphere as $18.2 \cdot 10^{22} \mathrm{~J}, 6.6 \cdot 10^{21} \mathrm{~J}$, and 8.1 . $10^{21} \mathrm{~J}$, respectively over the past half-century. However, the heat gain of the lithosphere via a heat flux across the solid surface of the continents ( $29 \%$ of the Earth's surface) has not been addressed. Here we calculate that component of Earth's changing energy budget, using ground-surface temperature reconstructions for the continents. In the last half-century there was an average flux of $39.1 \mathrm{~mW} \mathrm{~m}^{-2}$ across the land surface into the subsurface, leading to $9.1 \cdot 10^{21} \mathrm{~J}$ absorbed by the ground. The heat inputs during the last half-century into all the major components of the climate system - atmosphere, ocean, cryosphere, lithosphere-reinforce the conclusion that the warming during the interval has been global. INDEX TERMS: 1620 Global Change: Climate dynamics (3309); 1645 Global Change: Solid Earth; 1610 Global Change: Atmosphere $(0315,0325) ; 3322$ Meteorology and Atmospheric Dynamics: Land/atmosphere interactions; 3344 Meteorology and Atmospheric Dynamics: Paleoclimatology

\section{Introduction}

[2] The recent effort by Levitus et al. [2001] to quantify 20th century warming of the global climate system has yielded estimates of heat content increases within three of the system's major components: the oceans, atmosphere and cryosphere. In addition to these three, the continental lithosphere is another important component of the global climate system. The land-surface boundary represents $29 \%$ of the Earth's surface, plays a large role in heat and moisture transport between the air and ground, and influences radiatively important bieogeochemical cycles. Thus, an assessment of the heat gained within the global climate system is incomplete if the heat gained by the continents is not included in the accounting.

\section{The Continental Heat Flux}

[3] Here we use ground surface temperature histories (GSTHs) derived from deep borehole profiles to quantify the continental component of Earth's changing energy budget. Although there has been considerable work on the determination of GSTHs from geothermal data [Beltrami and Harris, 2001; Huang et al., 2000; Pollack and Huang, 2000] the extraction of temporal and spatial variations in the surface heat flux has not had equal consideration. Nearly two decades ago Lachenbruch et al. [1982] estimated the heat input to the permafrost of northern Alaska using subsurface temperatures. However, the subject has received relatively little attention until a formalism was recently established for estimating surface heat flux histories (SHFHs) directly from subsurface temperatures or from the associated GSTHs [Beltrami et al., 2000; Beltrami, 2001a, 2001b].

[4] Here we calculate the heat flux history over the surface of the continents for the past 500 years, with particular attention to the mean heat flux during 1950-2000, the interval of attention of the Levitus et al. [2001] calculations. We use an analytical representation derived from equations presented by Ingersoll et al. [1948] and Carslaw and Jaeger [1959] and employed by Lachenbruch et al. [1982]. This method of analysis permits the GSTH to have the form of a piece wise linear change of surface temperature with time, i.e. in the form of the Huang et al. [2000] five-century reconstruction shown in Figure 1. The surface flux change (relative to a prior steadystate) due to a GSTH comprising a series of temperature ramps is given by

$$
F\left(0, t_{n}\right)=\frac{2 \lambda}{\sqrt{\pi \kappa \Delta t}} \sum_{j=1}^{n} b_{j} \Delta t[\sqrt{n-j+1}-\sqrt{n-j}]
$$

where $b_{j}$ is the slope of a surface temperature ramp over a uniform time interval $\Delta \mathrm{t}, \lambda$ and $\kappa$ are the thermal conductivity and diffusivity of the ground respectively, and the time of observation, $\mathrm{t}_{n}$, is the sum of $\mathrm{n}$ uniform time steps of duration $\Delta \mathrm{t}$. The mean flux for any period of time follows from this

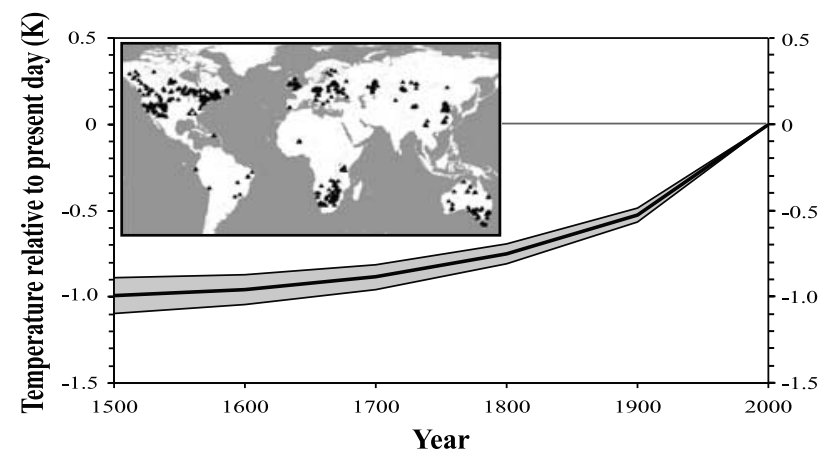

Figure 1. Global average of GSTH over the past five centuries. Shaded areas represent \pm 1 standard error about the mean. Inset shows the location of the 616 boreholes where subsurface temperature measurements have been analyzed to reconstruct the global GSTH. 


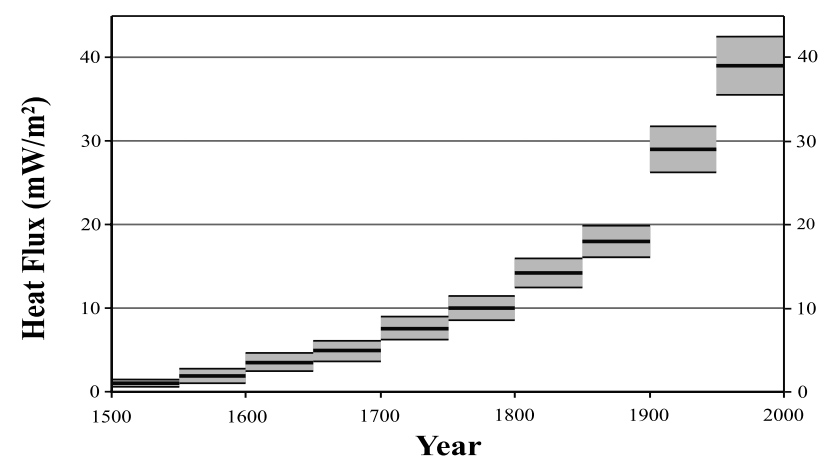

Figure 2. Global heat flux history inferred from the global average GSTH determined from subsurface temperature inversions. The mean heat flux over fifty-year intervals is shown as heavy black lines. The gray shaded areas represent the uncertainty about the means.

formulation by integrating over the time interval of interest. The GSTH used in this calculation [Huang et al., 2000], shown in Figure 1, was derived by inverting 616 borehole temperature profiles distributed over six continents. The inversion incorporated a parameterization of the GSTH in terms of century-long rates of surface temperature change that are shown as five linear ramps in Figure 1.

[5] In Figure 2 we show the surface flux history averaged over fifty-year intervals derived from (1). The mean fluxes for each fifty year interval are also given in Table 1 along with the corresponding heat gained by the continental lithosphere during each period. The total energy deposited into the continental lithosphere over the last five centuries sums to $3.0 \cdot 10^{22} \mathrm{~J}$. These fluxes indicate that $30 \%$ of the heat gained by the ground in the last five centuries was deposited during the last fifty years, and over half of the fivecentury heat gain occurred during the 20th century. However, the total energy gained by the continental lithosphere over the fivehundred year interval is less than the oceanic gain in the last fifty years.

[6] Figure 2 also shows the range of uncertainty in the halfcentury flux averages corresponding to the range of uncertainty in the GSTH shown in Figure 1. The uncertainties below and above the estimate of flux average in each half-century correspond to the -1 and +1 standard error bounds on the five century GSTH. The apparent increase in the uncertainty around the mean fluxes, over the five-century period, might seem counter-intuitive given the decreasing uncertainty with time in the surface temperature reconstructions from which the fluxes were calculated. However, the apparent inconsistency is resolved by noting the percent error of the fluxes, which decreases in time from approximately $49 \%$

Table 1. Mean Heat Flux into the Continental Lithosphere and the Corresponding Heat Gained in Fifty Year Intervals Over the Last Five Hundred Years

\begin{tabular}{ccc}
\hline Time Interval & Mean Heat Flux $\left(\mathrm{mW} \mathrm{m}^{-2}\right)$ & Heat Gain $\left(10^{21} \mathrm{~J}\right)$ \\
\hline $1950-2000$ & 39.1 & 9.1 \\
$1900-1950$ & 29.1 & 6.8 \\
$1850-1900$ & 18.0 & 4.2 \\
$1800-1850$ & 14.2 & 3.3 \\
$1750-1800$ & 10.0 & 2.3 \\
$1700-1750$ & 7.6 & 1.8 \\
$1650-1700$ & 4.9 & 1.1 \\
$1600-1650$ & 3.5 & 0.8 \\
$1550-1600$ & 1.9 & 0.4 \\
$1500-1550$ & 1.0 & 0.2 \\
& & \\
Total & & \\
\hline
\end{tabular}

Table 2. Comparisons of Heat Gain in Various Components of the Climate System

\begin{tabular}{ccc}
\hline Climate System Component & Time & Heat content increase $\left(10^{21} \mathrm{~J}\right)$ \\
\hline Word ocean & $1955-1996$ & 182.0 \\
Continental lithosphere & $1950-2000$ & 9.1 \\
Continental Glaciers & $1955-1996$ & 8.1 \\
Global atmosphere & $1955-1996$ & 6.6 \\
Antarctic sea ice & $1950 \mathrm{~s}-1970 \mathrm{~s}$ & 3.2 \\
Mountain glaciers & $1961-1997$ & 1.1 \\
& & $21.0 \cdot 10^{22} \mathrm{~J}$ \\
\hline
\end{tabular}

All values were taken from Levitus et al. [2001] except for our estimate of the heat gained by the continental lithosphere.

during the $1500-1550$ interval to about $9 \%$ during the $1950-$ 2000.

[7] We also recognize the possibility of additional uncertainty associated with the chosen value of average thermal conductivity that is required for this formulation. We have used the value $3.0 \mathrm{~W}$ $\mathrm{m}^{-1} \mathrm{~K}^{-1}$ which is very typical of a wide variety of common crustal rocks at near-surface temperatures [Cermak and Rybach, 1982]. A formal estimate of the uncertainty in the average thermal conductivity is difficult, but a $\pm 10 \%$ range would encompass most educated estimates. This variation has not been formally accounted for within the flux estimates given. Levitus et al. [2001] have also assessed the uncertainty in their own estimates, and the precision in their calculations is similar to the that which we present here. With specific attention to the 1950-2000 interval we calculate the mean value of the flux for the last half of the 20th century as $39.1 \pm$ $3.5 \mathrm{~mW} \mathrm{~m}^{-2}$. Integrated over the area of the continents for the fifty-year interval, this flux deposited $9.1 \pm 0.8 \cdot 10^{21} \mathrm{~J}$ into the continental crust. The result is shown in Table 2 along with the Levitus et al. [2001] values for the heat gain of the other major climate system components.

\section{Discussion and Conclusions}

[8] Table 2 indicates an integrated heat flux into the ground at least an order of magnitude smaller than the warming of the oceans, but on the same order of magnitude as observed within the atmosphere and various parts of the cryosphere during the latter half of the 20th century. The ocean has clearly seen the largest change in heat content during this period, but we suggest here that the lithosphere is an important constituent that should be considered in the accounting of the total heat gain within the global climate system. Our conclusions about the heat gain of the lithosphere, the last major component of Earth's climate system, are consistent with those presented by Levitus et al. [2001]. While the estimates may eventually be refined, their fundamental implication remains clear: all major components of the Earth's climate system have warmed over the last half century. This further supports the conclusion that the observed warming of Earth during the last fifty years has been truly global and extends upward into the atmosphere as well as downward into the Earth's oceans, cryosphere and continental crust.

[9] Acknowledgments. This research was supported by the Natural Sciences and Engineering Research Council of Canada (NSERC) through an operating grant to $\mathrm{HB}$ and by the National Science Foundation (NSF) through grant number ATM-0081864. We also acknowledge support from the International Geological Correlation Project 428.

\section{References}

Beltrami, H., Surface heat flux histories from geothermal data: Inference from inversion, Geophys. Res. Lett., 28, 655-658, $2001 \mathrm{a}$.

Beltrami, H., Surface heat flux histories from inversion of geothermal data: Energy balance at the Earth's surface, J. Geophys. Res., 106, 21,97921,994, 2001b. 
Beltrami, H., and R. N. Harris (Ed.), Inference of climate change from geothermal data, Global Planet. Change, 29, 148-352, 2001.

Beltrami, H., J. F. Wang, and R. L. Bras, Energy balanc eat the Earth's surface: Heat flux history in eastern Canada, Geophys. Res. Lett., 27, $3385-3388,2000$.

Carslaw, H. S., and J. C. Jaeger, Conduction of Heat in Solids, 2nd ed., 510 pp., Oxford Univ. Press, New York, 1959.

Cermak, V., and L. Rybach, Thermal conductivity and specific heat of minerals and rocks, in Landolt-Bornstein; Zahlenwerte und Funktionen aus Naturwissenschaften und Technik, edited by G. Angenheister, pp. 305-343 (Hrsg.) Bd. 1, Physikalische Eigenschaften der Gesteine, Teilbd. a., Springer-Verlag Berlin, Heidelberg, New York, 1982.

Huang, S., H. N. Pollack, and P. Y. Shen, Temperature trends over the last five centuries reconstructed from borehole temperatures, Nature, 403, 756-758, 2000.

Ingersoll, L. R., O. J. Zobel, and A. C. Ingersoll, Heat conduction with engineering and geological applications, pp. 278, McGraw-Hill, New York, 1948.

Lachenbruch, A., J. H. Sass, B. V. Marshall, and T. H. Moses Jr., Perma- frost, heat flow, and the geothermal regime at Prudhoe Bay, Alaska, J. Geophys. Res., 87, 9301-9316, 1982.

Levitus, S., J. Antonov, J. Wang, T. L. Delworth, K. Dixon, and A. Broccoli, Anthropogenic warming of the Earth's climate system, Science, 292, 267-270, 2001

Pollack, H. N., and S. Huang, Climate reconstructions from subsurface temperatures, Annu. Rev. Earth Planet. Sci., 28, 339-365, 2000.

H. Beltrami, Department of Earth Sciences, St. Francis Xavier University, P.O. Box 5000, Antigonish, Nova Scotia, Canada, B2G 2W5. (hugo@stfx. ca)

J. E. Smerdon, Applied Physics Program, University of Michigan, Ann Arbor, MI, 48109-1120, USA. (jsmerdon@umich.edu)

H. N. Pollack and S. Huang, Department of Geological Sciences, University of Michigan, Ann Arbor, MI, 48109-1063, USA. (hpollack@) umich.edu; shaopeng@umich.edu) 